\title{
The Need for a Deeper Notion of Holism in Complementary and Alternative Medicine
}

\author{
Hans A Baer* \\ Associate Professor, Division Arts, University of Melbourne, USA
}

*Corresponding author: Hans A Baer, Associate Professor, Division Arts, University of Melbourne, USA

Received Date: January 08, 2020

Published Date: February 26, 2021

\section{Short Communication}

I am writing this opinion piece from my perspective as a critical health and ecological anthropologist who has grappled since around 1980 with various CAM systems, particularly osteopathy, chiropractic, naturopathy, Chinese medicine, in the US, UK, and Australia, and more recently since 2005 with anthropogenic climate change. Both CAM and critical health anthropology are committed to the notion of holistic health and perhaps even planetary health, albeit in different ways. In reality, CAM is an amorphous category created by progressive biomedical physicians responding to the growing popularity of a wide array of alternative or heterodox health medical systems which found common cause under the umbrella of the holistic health movement in the $1970 \mathrm{~s}$ [1]. Integrative medicine also arose as a biomedical construction to supposedly blend the best elements of biomedicine and CAM and also adopted the notion of holism, but some would argue to co-opt various CAM systems [2,3]. What is desperately needed is an examination of how the various CAM systems define holistic health and health care. Nevertheless, my sense in having examined various CAM systems and medical pluralism for four decades is that CAM practitioners tend to view holism in terms of making mind-body-spirit connections, but often tend to either neglect or downplay the role of political, economic, and social structural, and environmental factors in disease etiology. Needless to say, there are exceptions to his observations. For example, the School of Natural and Complementary Medicine at Southern Cross University in Australia developed a Basic Model of (W)holistic Medicine in 1999 which recognises six elements in whole-person care: (1) physical, (2) mental, (3), spiritual, (4) family, (5) community, and (6) environment [4].

Critical health anthropology (CHA), formerly referred to as critical medical anthropology (CHA), understands health issues within the context of political and economic forces [5]. These forces are institutional, national, and global in scale. They pattern human relationships, shape social behaviours, condition collective experiences, reorder local ecologies, and situated cultural meanings. The emergence of CHA reflects both the turn toward political-economic and political-ecological approaches in anthropology in general beginning in the 1960 s, a period of social ferment around the globe, as well as an effort to engage with and extend the larger political economy of health approach. CHA seeks to provide a perspective and set of concepts for analysing macrointermediate-micro or global-national-local connections. At the macro level are the power relations of the capitalist world system and its associated corporate and state sectors coupled with plural medical systems; at the intermediate level are health institutions such as hospitals and clinics; and at the micro level are the healerpatient relationship and the patient experience.

CHA asserts that health ultimately must take precedence over health care, because the latter often comes into play once disease or illness has occurred. Critical health anthropologists define health in terms of access to and control over the basic material and nonmaterial resources that sustain and promote life at a high level of well-being. In essence, health is an elastic concept that must be considered within a larger sociocultural context. It is the product 
of a dialectical interaction of natural, political-economic, and sociocultural forces.

Disease or illness also varies from society to society, in some because of climatic and geographic conditions, but in large part because of the ways resources and productive activities are organised. It is not just the straightforward result of a pathogen, physiological, or anatomical disturbance as argued by biomedicine. Rather it is a result of a variety of social structural conditions all of which are ultimately roots in the capitalist world system with its emphasis on profit-making, continual economic growth, and a treadmill of production and construction that place tremendous pressure on the planetary ecosystem. Thus, disease and illness can result from malnutrition, social stratification, economic insecurity, alienation in the workplace, occupational risks, industrial and motor vehicle pollution, inferior housing, poor sanitation, the stress of everyday life, and environmental and climatic degradation.

CHA argues that the achievement of health with authentically and pluralistic health care requires the transcendence of global capitalism. It argues for the construction of a global democratic ecosocialist order that combines the principles of public ownership of the means of production, social equality, centralism, decentralism, representative and participatory democracy, environmental sustainability, and a safe climate [6]. CHA contends that progressive people, including health care workers, need to come to terms with both the achievements of post-revolutionary societies and to reconceptualize the notion of socialism. It recognizes that we live on an ecologically fragile planet with limited resources that must be shared and sustained and renewed for future generations. Ultimately, the shift to democratic eco-socialism would have to be part and parcel of global process that no one can fully envision.

Given the small size of complementary and alternative medicine in the various countries where it exists, CAM practitioners need to join forces with progressive biomedical practitioners as part of a larger process of advancing an authentically holistic health paradigm that recognizes that health and disease are ultimately embedded in political, economic, social structural, and ecological processes. Howard Waitzkin, a critical sociologist and progressive biomedical physician, argues: "Because of the powerful economic and political interests that dominate the health care system, the alternative movement cannot succeed unless it connects itself to broader political activism as well" [7]. In the US context, the creation of a universal health care system could pave the way to provide CAM therapies to working-class and poor people. In the case of countries with nationalized health care, such as Canada, the UK, Australia, and New Zealand, CAM therapies could be incorporated into an integrative health system in which biomedical and CAM practitioners work as co-equals in a collaborative relationship that blends an emphasis on both preventive and curative care. The larger struggle, however, is the creation of nationalized and holistic integrative health care systems in all countries as part of the struggle for a healthy planet.

\section{Acknowledgement}

None.

\section{Conflict of Interest}

Author declares no conflict interest.

\section{References}

1. Baer Hans A (2001) Biomedicine and Alternative Medicine in America: Issues of Class, Race/Ethnicity, and Gender. University of Wisconsin Press, USA.

2. Baer Hans A (2004) Toward an Integrative Medicine: Alternative Therapies Meet Biomedicine.

3. Baer Hans A (2009) Complementary Medicine in Australia and New Zealand. Verdant House, Queensland.

4. Myers Stephen P (2003) Naturopathic medicine. In Introduction to Complementary Medicine. In: T Robson (ed) Allen \& Unwin, Sydney.

5. Baer Hans A, Merrill Singer, Ida Susser (2013) Medical Anthropology and The World System: A Critical Perspective. Praeger, CA, USA.

6. Baer Hans A (2018) Democratic Eco-Socialism as a Real Utopia: Transitioning to Alternative World System. Berghahn Books, New York.

7. Waitzin Howard (2000) The Second Sickness: Contradictions of Capitalist Health Care. Rowan \& Littlefield, MD, USA. 